\title{
Patient Experience with Integrated Palliative Care Consult in Lung Transplant Evaluation Process
}

\author{
Alexandria J Robbins ${ }^{1,2 *}$, Todd Rockwood ${ }^{3}$, Fatima Alwan ${ }^{1}$, Gregory J Beilman ${ }^{4}$, Stephen \\ Huddleston $^{5}$, Nicholas Lemke ${ }^{5}$, Jagadish Patil ${ }^{6}$, Marshall Hertz ${ }^{6}$ and Drew Rosielle ${ }^{2,7}$ \\ ${ }^{1}$ Department of Surgery, University of Minnesota Medical School, USA \\ ${ }^{2}$ Department of Family Medicine \& Community Health, University of Minnesota Medical School, USA \\ ${ }^{3}$ Division of Health Policy and Management, University of Minnesota School of Public Health, USA \\ ${ }^{4}$ Department of Surgery, University of Minnesota Medical School, USA \\ ${ }^{5}$ Department of Surgery, Division of Cardiothoracic Surgery, University of Minnesota Medical School, USA \\ ${ }^{6}$ Department of Medicine, Division of Pulmonology, University of Minnesota Medical School, USA \\ ${ }^{7}$ Department of Internal Medicine, University of Minnesota Medical School, USA
}

\begin{abstract}
Background: Several prominent societies have published statements promoting earlier integration of palliative care for patients with advanced lung disease. Our institution recently added palliative care consultation to the lung transplant evaluation process.
\end{abstract}

Study Design: Patients ( $\mathrm{n}=153)$ who underwent lung transplant evaluation were sent surveys. Of those, 29 had died, 10 asked to be excluded and 45 (36\%) completed the survey. This included the 15-item Advance Care Planning (ACP) Engagement survey, a validated tool to assess readiness and self-efficacy.

Results: The ACP-engagement survey showed high self-efficacy and readiness. Regarding potential bad outcomes after lung transplant, palliative care helped them feel more informed (63\%

OPEN ACCESS

*Correspondence: Alexandria J Robbins, Department of Surgery, University of Minnesota Medical School, 420 Delaware St SE, MMC 195, Minneapolis, USA, Tel:

9522157223;

E-mail: cough083@umn.edu Received Date: 05 Nov 2021 Accepted Date: 26 Nov 2021 Published Date: 09 Dec 2021

Citation:

Robbins AJ, Rockwood T, Alwan F, Beilman GJ, Huddleston S, Lemke N, et al. Patient Experience with Integrated

Palliative Care Consult in Lung Transplant Evaluation Process. Ann Palliat Care Med. 2021; 2(1): 1008.

Copyright $\odot 2021$ Alexandria J

Robbins. This is an open access article distributed under the Creative Commons Attribution License, which permits unrestricted use, distribution,

and reproduction in any medium, provided the original work is properly cited. "extremely") and ready/prepared (59\% "extremely"). A t-test compared mean scores between lung transplant provider team members. Pulmonologists were the most likely to help participants feel both informed and ready \& prepared for potential bad outcomes $(\mathrm{p}=0.02)$. Overall, participants reported that the palliative care consult had a high impact.

Conclusion: The palliative care visit specifically offered benefit in patient and medical decision maker preparation for potential bad outcomes, independent of their ACP engagement and knowledge about the visit beforehand.

Keywords: Surgical palliative care; Lung transplant; Preparedness planning; Palliative care

\section{Introduction}

Patients with advanced lung disease face a high symptom burden and a poor overall prognosis [1]. The International Guidelines for the selection of lung transplant candidates suggest referral for lung transplantation in patients with a less than $50 \% 2$ to 3 year predicted survival or New York Heart Association class III or IV level of function, which categorizes patients who have severe limitations with walking short distances or are only comfortable at rest [2]. A study by Egan and Edwards found that an average of 300 patients die annually while waiting for lung transplants [3]. Despite advancements in the field of lung transplantation, even patients who do receive a transplant have a median survival of 6.7 years post-transplant [4]. The International Society for Heart and Lung Transplant Registry recently reported that in adult patients transplanted since 2010 there was an $85 \%$ and $59 \% 1$ and 5-year survival respectively [4].

Many patients view lung transplantation as a measure to improve quality of life even when extended survival is not assured [5]. These patients live with debilitating symptoms such as dyspnea, gastroesophageal reflux, supplemental oxygen dependence, and social isolation with resultant psychological and emotional impacts [1]. Many studies have reported significant improvements in both generic and respiratory-specific health-related quality of life post-lung transplant [6]. Most of the quality-of-life improvements are in physical function, general health and social function 
with more modest gains in mental health outcomes [6]. Very few quality-of-life studies reports results later than three years post lung transplant which is notable because they may not account for the impact of chronic lung allograft dysfunction, which is seen in $50 \%$ of patients at 5 years post-transplant [6]. Other complications seen in post-transplant patients include renal failure, infections related to continued immunosuppression, and malignancy [4].

The American College of Chest Physicians and the American Thoracic Society have published statements emphasizing the importance of palliative care in lung transplant patients [5]. In fact, the American Thoracic Society's Clinical Policy Statement recommends that "palliative care should begin when a patient becomes symptomatic and is usually concurrent with restorative and life-prolonging care [7]." Current literature regarding the role of palliative care in lung transplantation patient management is primarily composed of singlesite retrospective reviews of the impact of consultation on symptom management and surveys of providers about barriers to involving palliative care [8-11]. A review of the existing literature by Pawlow et al. found that palliative care was rarely consulted and was most often consulted late in the transplant process [12].

Our institution started routinely incorporating palliative care consultation in the lung transplant evaluation process. Currently, there is no existing literature that examines the patient's perspective on palliative care's involvement in the lung transplant evaluation process or palliative care's potential benefit in prompting advance care planning in this population. Our study aimed to learn more about patients' perceptions of involving the palliative care team prior to lung transplant listing. Specifically, we hypothesized that the palliative care team would improve advance care planning engagement and aid patients and their surrogates in preparing for lung transplant.

\section{Methods}

Starting in the summer of 2018, a palliative care consult or referral was added to the lung transplant evaluation process at $M$ Health Fairview which is a joint enterprise with the University of Minnesota. This study and consent process was approved by the University of Minnesota's Institutional Review Board (STUDY00006507). We reviewed our electronic medical record for all patients who underwent lung transplant evaluation from January 2018 to February 2020 at our institution. A mixed mode approach was used to conduct the study; in which an initial wave of patients $(n=68)$ were sent paper surveys in the mail. Due to a low response $(n=15)$, patients were subsequently sent an e-mail invitation to complete the survey electronically [13]. Our reported percentage response rate included the patients who asked to be excluded in the denominator per the American Association for Public Opinion Reporting Guidelines. An informed consent and HIPAA paper form were included in the paper surveys sent to participants. In the online survey there was informed consent information in the email and the initial online page that participants had to view and agree to in order to access the survey Both forms of consent were approved by the University of Minnesota's Institutional Review Board. Our study design strictly complied with the International Society for Heart and Lung Transplantation Ethics Statement.

An example of the 25-question survey sent to patients is included in the Appendix. The initial questions included the 15-item Advance Care Planning (ACP) Engagement survey, a validated tool that draws from Social Cognitive and Behavioral change theories. The survey evaluates several parts of ACP including: Identifying surrogates, patient's values and definition of quality of life, flexibility afforded to their surrogate to adjust to contemporaneous circumstances and comfort in asking follow up questions of their medical team [1416]. The questions are classified as either readiness or self-efficacy questions with answers on a five-point Likert scale, within each group of questions the average Likert score is calculated and reported. The readiness question's answers correlate with the stages of behavioral change, with a Likert score of 3, 4, and 5 matching to contemplation, preparation, and action respectively $[17,18]$. In the readiness questions, the potential answers range from 1- "never thought about it" to 5- "I have already done it". An example question is "how ready are you to formally ask someone to be your medical decision maker?" In our study, if "I have already done it" was selected, a follow up question was prompted which asked if this was done before or after the palliative care visit.

We created an additional set of questions specific to the palliative care consult's role in being ready and informed for lung transplant. These questions utilized a five-point Likert scale and were analyzed using mean and standard deviation. Two questions compared palliative care to other lung transplant team members' role in helping patients feel ready and informed about potential lung transplant outcomes. These relationships were compared using t-test analysis, and basic correlational evaluation was performed using Kendall tau B correlation co-efficient. Finally, there was one free text question included at the end.

Demographic data were obtained including age, sex, race, and current lung transplant status. Participants who responded to the survey were compared to patients who did not. Continuous variables were reported as mean and Standard Deviation (SD), then compared using Student's $t$ test. Categorical variables were reported using $\mathrm{n}$ and percentages, then compared using Pearson's Chi square or Fisher's exact tests. Statistical analysis was performed using SAS $^{\odot}$.

\section{Results}

Of the 153 patients who underwent lung transplant evaluation at our institution from January 2018 to February 2020, 29 patients had died by the end of the study, and 10 asked to be excluded (Figure 1). There were 15 paper responses and 30 online responses (36\% response rate). The average age of the respondents was 58.6 years old, $38 \%$ were female and $93 \%$ were white (Table 1). A non-response evaluation showed no significant socio-demographic differences between respondents and non-respondents (Table 1) [19]. At the time that the surveys were sent out, $49 \%$ of respondents had undergone transplant, $24 \%$ were on the waitlist and $27 \%$ were still being evaluated.

Regarding the Advance Care Planning Engagement Survey results, the average self-efficacy score was high at 4.6 (SD 0.5). The average readiness score was 3.7 (SD 1.1) which would indicate the "preparation" stage of behavior change. In response to the readiness question in participants who responded "I have already done it", 19\% to $37 \%$ reported that this step was completed only after the palliative care visit (Supplemental Table 1). One participant reported that 'this meeting was a great way to discuss end-of-life issues."

Two questions asked about preparation for the palliative care visit it with the average responses being 3.32 to 3.5 indicating that participants were somewhat ready and informed for the visit (Table 2). A participant highlighted the importance of introducing the 
Table 1: Demographic Information.

\begin{tabular}{|c|c|c|c|}
\hline & Respondents $(n=45)$ & Did Not Respond $(n=69)$ & $\mathbf{P}$ \\
\hline Age (years) - Mean (SD) & $58.6(10.0)$ & $58.0(11.0)$ & 0.77 \\
\hline Sex (Female) - n (\%) & $17(38)$ & $29(42)$ & 0.7 \\
\hline Race & & & 0.06 \\
\hline White & $42(93)$ & $55(80)$ & \\
\hline African American & $1(2)$ & $7(10)$ & \\
\hline American Indian or Alaska Native & $1(2)$ & $5(7)$ & \\
\hline Asian & $0(0)$ & $1(1)$ & \\
\hline Choose not to Answer & $1(2)$ & $1(1)$ & \\
\hline Current Status on Transplant List & & & 0.24 \\
\hline Evaluation & $12(27)$ & $26(38)$ & \\
\hline Transplanted & $22(49)$ & $30(43)$ & \\
\hline
\end{tabular}

Table 2: Palliative care specific questions.

\begin{tabular}{|c|c|c|c|}
\hline & Mean & SD & $\mathbf{n}$ \\
\hline How ready did you feel for your palliative care visit? & 3.50 & 1.23 & 36 \\
\hline How informed were you about what the palliative care visit was about? & 3.32 & 1.16 & 37 \\
\hline $\begin{array}{l}\text { As a result of my palliative care visit, I have a better understanding of what challenges I could face if I don't have a good outcome from } \\
\text { my transplant. }\end{array}$ & 3.97 & 1.24 & 37 \\
\hline As a result of my palliative care visit, I am better prepared to consider what my options are if I have a bad outcome after my transplant. & 3.89 & 1.31 & 37 \\
\hline $\begin{array}{l}\text { After the palliative care visit, how much confidence do you have that your surrogate or medical decision maker would make the same } \\
\text { decisions that you would? }\end{array}$ & 4.43 & 0.90 & 37 \\
\hline After the palliative care visit, I feel that my caregiver has a better understanding of what could happen after a lung transplant. & 3.86 & 1.32 & 37 \\
\hline $\begin{array}{l}\text { After the palliative care visit, I feel that my decision maker is more prepared to make any potential medical decisions on my behalf after } \\
\text { lung transplant. }\end{array}$ & 3.86 & 1.56 & 21 \\
\hline In general, I would say that the palliative care visit was a good experience. & 4.14 & 1.22 & 37 \\
\hline
\end{tabular}

Answers ranged from 1 - Not at all to 5 - Extremely or Very Ready/Informed depending on the question.

SD: Standard Deviation

Table 3: Free text answers - illustrative quotes.

Question: "Thank you for taking the time to participate in this important study. Is there anything else that you would like us to know about your experience with palliative care?"

\begin{tabular}{|l|l|}
\hline \multicolumn{1}{|c|}{ Theme } & \multicolumn{1}{c}{$\begin{array}{l}\text { Quote } \\
\text { experience with palliative care?" }\end{array}$} \\
\hline $\begin{array}{l}\text { Advanced Care Planning } \\
\text { Engagement }\end{array}$ & $\begin{array}{l}\text { ". I made decisions regarding my medical directive prior to meeting with palliative care in preparation for my long-term care meeting with } \\
\text { my CF team. My medical decision maker, back-up and doctor were at the meeting so we talked through everything - I had my living will } \\
\text { at the meeting and had a copy placed in my medical record. This meeting was a great way to discuss end-of-life issues." } \\
\text { "More information on the palliative care visit in advance would have helped me form my thoughts on the subject before the meeting. I } \\
\text { went into the visit without knowing for sure what the meeting was going to be about. Information on "what is palliative care?"” } \\
\text { "My palliative care visit was scheduled at a later time from my other visits which caused a lot of anxiety because when they told me I } \\
\text { needed to see palliative care, I assumed I was going to die. Please incorporate palliative care with another doctors visit and don't tell } \\
\text { the patient about palliative care until that time." }\end{array}$ \\
\hline Preparation for the visit & $\begin{array}{l}\text { "I had previously made my decisions about my medical care but after the palliative appointment I had to change some of my previous } \\
\text { decisions." } \\
\text { "The information provided is essential in understanding the outcomes of the transplant process and what should be in place before } \\
\text { entering surgery." } \\
\text { "All people involved were extremely professional and knowledgeable. Very friendly." } \\
\text { "It is a necessary part of the preparation process :). " } \\
\text { "Very worthwhile visit. Learned much more than expected." } \\
\text { "Thank you for taking the time to add this important visit to our work-up week." }\end{array}$ \\
\hline Overall Experience &
\end{tabular}

palliative care consult saying: "My palliative care visit was scheduled at a later time from my other visits which caused a lot of anxiety because when they told me I needed to see palliative care, I assumed I was going to die."

Questions about participant preparedness for potential challenges and understanding of options in the event of a bad outcome after the palliative care visit ranged from 3.89 to 3.97 . One participant offered that "The information provided is essential in understanding the outcomes of the transplant process and what should be in place before entering surgery." Additional free text answers provided in Table 3.
Questions about the participant's perception of caregiver and medical decision makers understanding of potential bad outcomes and their preparation for making decisions after the palliative care consult were both 3.86. The highest score of 4.43 was for patient and medical decision maker predicted decision concordance after the visit. Finally, participants said that overall the palliative care visit was a good experience with an average score of 4.14.

Next, the impact of the various lung transplant provider team members was compared. Palliative care specifically helped respondents feel more informed (63\% "extremely", 4.2+1.3) and 
Table 4: Impact of the palliative care consult.

\begin{tabular}{|c|c|c|c|}
\hline $\begin{array}{l}\text { How much did each of the following groups help you feel informed about potential bad outcomes after lung } \\
\text { transplant? }(n=35)^{*}\end{array}$ & Mean difference & SD & P-value \\
\hline Pulmonologists & -0.46 & 1.09 & 0.02 \\
\hline Surgeons & -0.20 & 1.18 & 0.32 \\
\hline Nurse Coordinators & -0.26 & 1.20 & 0.21 \\
\hline Social Workers & -0.06 & 1.30 & 0.80 \\
\hline $\begin{array}{l}\text { How much did each of the following groups help you feel ready and prepared for potential bad outcomes after } \\
\text { lung transplant? }(n=37)^{\star}\end{array}$ & Mean difference & SD & P-value \\
\hline Pulmonologists & -0.46 & 1.14 & 0.02 \\
\hline Surgeons & -0.30 & 1.15 & 0.13 \\
\hline Nurse Coordinators & -0.27 & 1.33 & 0.22 \\
\hline Social Workers & -0.03 & 142 & 0.91 \\
\hline
\end{tabular}

${ }^{*}$ Relative to Palliative Care, a negative mean difference implies more helpful than the refence group palliative care SD: Standard Deviation

ready/prepared (59\% "extremely", 4.0+1.4) for potential bad outcomes after lung transplant. Palliative care scored slightly lower than the surgeons, social workers and nurse coordinators (mean Likert score difference 0.06 to 0.46 ). The pulmonologists were the only group that was statistically significantly more likely to help respondents feel informed $(\mathrm{p}=0.02)$ and ready \& prepared $(\mathrm{p}=0.02)$ for potential bad outcomes after lung transplant relative to palliative care (Table 4). Pulmonologists were then compared with other team members; they remained statistically significantly more likely to help participants feel informed than all other groups. Pulmonologists also were more likely than all other groups to help participants feel ready and prepared for potential bad outcomes after lung transplant; however, there was not a statistically significant difference between the pulmonologists and nurse coordinators (Supplemental Table 2).

The ACP Engagement self-efficacy and readiness responses were not correlated with how participants responded to questions about whether the palliative care visit prepared them for potential lung transplant bad outcomes ( $\mathrm{p}$ values all $>0.05$ ). How prepared respondents felt for the visit was not statistically significantly related to the responses for how well the palliative care visit helped prepare them for potential bad outcomes post lung-transplant, in fact there was a negative correlation (Supplemental Table 3). Importantly, there was congruence between the responses to palliative care's specific role within the lung transplant team in preparing for bad outcomes and the responses to the specific questions about the palliative care visit (all $\mathrm{p}$ values $<0.05$, Supplemental Table 3 ). The highest correlation was between finding the palliative care team helpful overall and the participant expressing a better understanding of challenges and options available in the event of a bad outcome post lung transplant (Supplemental Table 3).

\section{Discussion}

To some patients and clinicians, the concept of incorporating palliative care into the lung transplant evaluation process may seem paradoxical to their clear intent of restorative goals inherent in pursuing a transplant. However, not all of these patients will receive a transplant and those who do continue to have a significant risk of morbidity and mortality [2,4]. In our study, $19 \%$ had died (29/153) at the time that the surveys were sent out which ranged from one to eighteen months from the time of initiating the lung transplant evaluation process. Of those remaining, 33\% (26/114) were still being evaluated and $21 \%(24 / 114)$ were on the waitlist. We did not ask about post-transplant outcomes in the $46 \%$ (52/115) who had been transplanted. Given the poor prognosis of this population, the emotional burden of waiting for transplant and the associated potential complications post-transplant this population is uniquely poised to benefit from ongoing specialty palliative care services $[2,4,11,12,20]$. Our institution aims to connect patients with advanced lung disease to the ongoing support and resources of the hospice and palliative teams through this introductory consultation during the lung transplant evaluation process. The University Health Network recently reported on their experience running a unique specialty transplant palliative care clinic [21].

Our institution models the pre-lung transplant palliative care visit after the preparedness planning performed prior to Left Ventricular Assist Device placement (LVAD) [22]. This visit typically includes a review of symptom management, assessment of disease and prognosis understanding, and coping skills. The majority of the visit is spent on advance care planning with a specific emphasis on patient's goals and values related to complications seen after lung transplantation (side effects of immunosuppression, renal failure, and chronic mechanical ventilation). The advance care planning includes reviewing any healthcare directives, identifying a surrogate, determining the patient's definition of a good quality of life and reviewing any unacceptable health statuses (i.e. "vegetative state", tracheostomy etc.). In our study, participant responses to the ACP Engagement tool demonstrated high self-efficacy and readiness that correlated with the "preparation" stage of behavior change [18]. Notably, in response to the various readiness questions 19\% to $37 \%$ reported that they completed various ACP tasks only after completing the palliative care visit.

The participants in our study, on average, described having only some understanding about their palliative care consult prior to their visit. This is unsurprising as previous studies indicate that palliative care involvement is still rare in this population [23,24]. Respondents in our study reported that the visit helped them have a better understanding of potential bad outcomes post lung transplant. Interestingly, the negative correlation between participant's previous understanding of palliative care and the perceived preparation for possible bad outcomes gained through the visit, suggests that those participants who knew less about palliative care prior to their visit trended towards reporting a greater value from the visit.

Informed consent for surgeries that are as high-risk and life 
changing (immunosuppression) as lung transplant can be difficult to obtain [25-27]. It is understandably intimidating to grasp the gravity of the anticipated change or risks, particularly in a patient population that is desperate for symptom relief and the opportunity for more time [25-27]. Moloney et al. [27] performed an interview study of patients and surrogates about the process of deciding to pursue lung transplant. In lung transplant recipients with a long recovery or who developed complications reported that "they would have benefited from being more prepared for their post-transplant experiences” [27]. Palliative care specialists receive extensive training in communication about elucidating a patient's values and aiding the patient in applying those values to discuss theoretical outcomes [1]. This could be one of the unique contributions that palliative care can bring to the lung transplant team. Participants reported that they found the palliative care visit similarly helpful to team members, other than the pulmonologists who had a larger impact on respondents. This is notable because the palliative care team spends roughly an hour with these patients relative to the longer-term relationships with other providers.

Participants also reported that their surrogate decision makers have a better understanding of potential bad outcomes post lung transplant. Participants in this study felt strongly that the visit helped align the participant and the surrogate about the patient's goals of care. This is arguably the most important step of advance care planning, in promoting confidence of the patient in their surrogate's ability to use substituted judgment appropriately. A recent study with 200 subjects, surveyed patients in the perioperative period and their surrogates [28]. They asked about the patient's preferences around intensive treatments ( $\mathrm{CPR}$, hemodialysis etc.) and unacceptable health statuses (cognitive or physical disability etc.). Concordance was highest around CPR in $84 \%$ of patients and their surrogates; however, in the six other domains there was $<60 \%$ concordance. There was no statistically significant improvement in concordance in the $59 \%$ of pairing who reported completing prior conversations about the patient's wishes [28]. This suggests that simply asking about the presence of a surrogate, healthcare directive, or previous advance care planning conversations is likely insufficient. Palliative care consultation supplements the lung transplant team by facilitating an explicit discussion between the patient and surrogate about potential complications in the post-operative period. Importantly, they also document the conversation for future reference of the surrogate or medical teams.

This study has several limitations. This study was limited to a single hospital system and had only a $36 \%$ response rate. The participants were $62 \%$ male and $93 \%$ white, the Organ Procurement and Transplantation Network reported that in 2017 in the United States of patients listed for lung transplant 59\% were female and $74 \%$ were white [29]. Additionally, while the difference did not reach statistical significance, the respondents were less likely to be African American (2\% vs. 10\% non-respondents) or American Indian/Alaskan Native (2\%vs. $7 \%$ non-respondents). The intent of this study was to be exploratory; however, this is the first look at patient perception of including palliative care in the lung transplant evaluation process. While our study suggests that participants found the palliative visits acceptable and helpful, a prospective randomized trial would be required to measure the specific contribution attributable to the palliative care team. Future work should include the perspective of the surrogate decision maker or support person as well as the specific assessment of the value of the palliative care visit in patients who have more favorable outcomes versus those who do not.

\section{Acknowledgement/ Funding}

Research by GB is funded by the National Institute of Health (T32DK108733). Research by GB and AR are funded by Department of Defense (W81XWH18106872).

\section{References}

1. Rocker GM, Simpson AC, Horton R. Palliative care in advanced lung disease: The challenge of integrating palliation into everyday care. Chest. 2015;148(3):801-9.

2. Orens JB, Estenne M, Arcasoy S, Conte JV, Corris P, Egan JJ, et al. International guidelines for the selection of lung transplant candidates: 2006 update--a consensus report from the pulmonary scientific council of the international society for heart and lung transplantation. J Heart Lung Transplant 2006;25(7):745-55.

3. Egan TM, Edwards LB. Effect of the lung allocation score on lung transplantation in the United States. J Heart Lung Transplant. 2016;35(4):433-9.

4. Bos S, Vos R, Van Raemdonck DE, Verleden GM. Survival in adult lung transplantation: Where are we in 2020? Curr Opin Organ Transplant. 2020;25(3):268-73.

5. Singer JP, Singer LG. Quality of life in lung transplantation. Semin Respir Crit Care Med. 2013;34(3):421-30.

6. Thabut G, Mal H. Outcomes after lung transplantation. J Thorac Dis. 2017;9(8):2684-91.

7. Lanken PN, Terry PB, DeLisser HM, Fahy BF, Hansen-Flaschen F, Heffner JE, et al. An official American thoracic society clinical policy statement: Palliative care for patients with respiratory diseases and critical illnesses. Am J Resp Crit Care Med. 2008;177(8):912-27.

8. Colman RE, Curtis JR, Nelson JE, Efferen L, Hadjiliadis D, Levine DJ, et al. Barriers to optimal palliative care of lung transplant candidates. Chest. 2013;143(3):736-43.

9. Colman R, Singer LG, Barua R, Downar J. Outcomes of lung transplant candidates referred for co-management by palliative care: A retrospective case series. Palliat Med. 2015;29(5):429-35.

10. Freeman N, Le LW, Singer LG, Colman R, Zimmermann C, Wentlandt K. Impact of a transplant palliative care clinic on symptoms for patients awaiting lung transplantation. J Heart Lung Transplant. 2016;35(8):10379.

11. Gustafson C, Song MK. State of the science of palliative care in solid organ transplantation. Prog Transplant. 2020;30(4):382-95.

12. Pawlow PC, Doherty CL, Blumenthal NP, Matura LA, Christie JD, Ersek M. An integrative review of the role of palliative care in lung transplantation. Prog Transplant. 2020;30(2):147-54.

13. Dillman DA, Jolene DS, Leah MC. Internet, phone, mail, and mixed-mode surveys: The tailored design method. John Wiley \& Sons. 2014.

14. Sudore RL, Knight SJ, McMahan RD, Feuz M, Farrell SD, Miao Y, et al. A novel website to prepare diverse older adults for decision making and advance care planning: A pilot study. J Pain Symptom Manage. 2014;47(4):674-86.

15. Sudore RL, Stewart AL, Knight SJ, McMahan RD, Feuz M, Miao Y, et al. Development and validation of a questionnaire to detect behavior change in multiple advance care planning behaviors. PLoS One. 2013;8(9):e72465.

16. Shi Y, Barnes DE, Boscardin J. Brief English and Spanish survey detects change in response to advance care planning interventions. J Pain Symptom Manage. 2019;58(6):1068-74.

17. Sudore RL, Heyland DK, Barnes DE. Measuring advance care planning: Optimizing the advance care planning engagement survey. J Pain 
Symptom Manage. 2017;53(4):669-81.

18. Fried TR, Redding CA, Robbins ML, Paiva A, O'Leary JR, Iannone L. Stages of change for the component behaviors of advance care planning. J Am Geriatr Soc. 2010;58(12):2329-36.

19. Luiten A, Joop H, de Leeuw E. Survey non response trends and fieldwork effort in the $21^{\text {st }}$ Century: Results of an international study across countries and surveys. J Office Stats. 2020;36(3):469-87.

20. Skogeland U, de Monestrol I, Godskesen TE. Experiences of individuals awaiting lung transplantation. Respir Care. 2018;63(12):1535-40.

21. Wentlandt K, Dall'Osto A, Freeman N, Le LW, Kaya E, Ross H, et al. The transplant palliative care clinic: An early palliative care model for patients in a transplant program. Clin Transplant. 2016;30(12):1591-6.

22. Swetz KM, Kamal AH, Matlock DD, Dose AM, Borkenhagen AS, Kimeu AK, et al. Preparedness planning before mechanical circulatory support: A "how-to" guide for palliative medicine clinicians. J Pain Symptom Manage. 2014;47(5):926-35.

23. Song MK, De Vito Dabbs A, Studer SM, Arnold RM. Palliative care referrals after lung transplantation in major transplant centers in the United States. Crit Care Med. 2009;37(4):1288-92.
24. Nolley EP, DeSensi R, Nouraie M, Schenker Y, Morrell MR. Characteristics, trends, and predictors of specialty palliative care utilization after lung transplantation. J Palliat Med. 2019;22(9):1092-8.

25. Dellon EP, Shores MD, Nelson KI, Wolfe J, Noah TL, Hanson LC. Caregivers' perspectives on decision making about lung transplantation in cystic fibrosis. Prog Transplant. 2009;19(4):318-25.

26. Vandemheen KL, O'Connor A, Bell S, Freitag A, Bye P, Jeanneret A, et al. Randomized trial of a decision aid for cystic fibrosis patients considering lung transplantation. Am J Respir Crit Care Med. 2009;180(8):761-8.

27. Moloney S, Cicutto L, Hutcheon M, Singer L. Deciding about lung transplantation: Informational needs of patients and support persons. Prog Transplant. 2007;17(3):183-92.

28. Udelsman BV, Govea N, Cooper Z, Chang DC, Bader A, Meyer MJ. Concordance in advance care preferences among high-risk surgical patients and surrogate health care decision makers in the perioperative setting. Surgery. 2020;167(2):396-403.

29. Valapour M, Lehr CJ, Skeans MA, Smith JM, Miller M, Goff R, et al. OPTN/SRTR 2019 annual data report: Lung. Am J Transplantation. 2019;21(2):441-520. 